\title{
Elite Tweets: Analyzing the Twitter Communication Patterns of Labour Party Peers in the House of Lords
}

\author{
Ana Adi, Kristofer Erickson, and Darren G. Lilleker
}

\begin{abstract}
The micro-blogging platform Twitter has gained notoriety for its status as both a communication channel between private individuals and as a public forum monitored by journalists, the public, and the state. Its potential application for political communication has not gone unnoticed; politicians have used Twitter to attract voters, interact with constituencies and advance issue-based campaigns. This article reports findings from the research team's work with 21 peers sitting on the Labour frontbench. The researchers monitored and archived the peers' activity on Twitter for a period of 3 months between June and September 2012. Using a sample of 4,363 tweets and a mixed methodology combining semantic analysis, social network analysis, and quantitative analysis, this article explores the peers' patterns of usage and communication on Twitter. Key findings are that as a tweeting community their behavior is consistent with other communities. However, there is evidence that a coherent strategy is lacking in their coordinated use of the platform. Labour peers tend to work in small, clustered networks of self-interest as opposed to collectively to promote party policy.
\end{abstract}

KEY WORDS: Twitter, social network analysis, House of Lords, elite groups, semantic analysis, U.K. Labour Party

\section{Introduction}

Political communication scholarship has devoted considerable attention to the impact of participatory Web platforms on the practice of politics. Perhaps the most consequential feature of participatory and social media platforms is that they can foster two-way dialogic communication between politicians and publics. This feature of digital communication has led to intense debate about whether and how much social media platforms can widen or flatten political participation. Opportunities for democratic participation are embodied in these services' ubiquity and global reach: lowering the commitment threshold may create new opportunities for political mobilization (Bakardjieva, 2009; Karpf, 2010), while social movements and issue campaigns can "jump scales" to find adherents across social and geographical distances (Brenner, 1999). On the other hand, hindrances to flatter democratic participation include the ongoing salience of a 
"skills gap" between highly- and less-influential users of platforms, and the observed tendency of influence to be skewed in favor of a smaller number of highly networked individuals in any given online community (Hindman, 2009; Tremayne, Zheng, Lee, \& Jeong, 2006).

A number of authors have suggested that one's preexisting social capital is determinant in amplifying one's ability to project messages in online contexts (Boyd \& Heer, 2006; Ellison, Lampe, Steinfield, \& Vitak, 2011). It would appear that politicians are naturally favored in such online settings, because they come to platforms with a public presence which-for better or worse-assures at least some interest in their online communiqués. Research on political campaigning supports the notion that traditional media exposure synergistically amplifies online reach, while online messages likewise find their way back into traditional media channels (Howard, 2006). But how uniformly advantaged are political elites in online social settings, and how does that advantage translate to effective political communication?

This article contributes to a growing volume of research that seeks to compare the patterns of social media use between political actors of similar status (Hemphill, Ottenbacher, \& Shapiro, 2012; Jürgens, Jungherr, \& Schoen, 2011). As part of a knowledge exchange initiative by Bournemouth University, the authors gained access to a selection of 21 Labour Party members of the U.K.'s House of Lords who use the microblogging platform Twitter as part of their political activity. The participants in the study, who were all self-selecting, gave permission for their tweets to be tracked and recorded for the study period, which lasted for 3 months from June 20 to September 28, 2012.

Building on the concepts of agenda setting, mediatization, and framing, we seek to compare the Twitter usage and reach of individual Lords and evaluate the effectiveness of the sample as a whole when using Twitter to advance Labour Party policy and messages. Our findings suggest that there are at least two layers of "elite" status in politicians' use of Twitter. The status of the Lords group as elites in U.K. society provides them with a capacity for agenda setting in social media, particularly by communicating directly with other influentials such as journalists. However, the enthusiasm of individual Lords for Twitter, as well as their ability to gain a command of its mediatizing effects, are not evenly shared. We identify a second, elite clique of super-users within our sample who are able, to a certain extent, to set the agenda for other Lords and the media by constructing their messages appropriately and by maximizing the reach of their online social networks. We end the article by discussing the particular features of practice that seem to privilege these super-user voices, and we speculate on the impacts of the observed disparity for collective political campaigning in social media.

\section{The Lords-An Anachronistic Elite}

The House of Lords is Britain's upper chamber; members are largely appointed by the Queen on recommendations from the party leaders of the day; 
however, once appointed they remain in the chamber for life. The Lords tend to be organized along party lines; of the 781 members, 222 are Conservative, 221 Labour, 99 Liberal Democrat, and 14 are affiliated to other parties. However, there are also 202 Lords who classify themselves as crossbenchers or unaffiliated, as well as the 23 Lords Spiritual, senior bishops who eschew party lines. The Lords are unable to make or block policy entirely; they act as scrutinizers who debate and recommend amendments to legislation put forward by the lower house, the House of Commons. Lords from the main parties tend to operate as a mirror of the Commons, each with a front bench of spokespersons who promote their party policy or party line when scrutinizing legislation.

As a chamber, the Lords tend to be seen as an anachronism and so tend to be marginalized from the mainstream news agenda. The Labour frontbenchers are actively attempting to counter this notion. Through a proactive multimedia management strategy, utilizing a weblog (www.labourlords.org.uk), an aggregated Labour Lords Twitter feed (@LabourLordsUK), as well as extant contacts with journalists and attention-capturing activities, the Labour Lords seek to extend the critical message of the Labour party on the program of the current Conservative and Liberal Democrat coalition government. Thus, this group of Lords is attempting to break from the image of having a largely symbolic function, to demonstrating the party political and cheerleading function for their party that the Labour leadership expects of them. It is within this context that we investigate the extent that these political actors are using Twitter as a strategic tool, while also reflecting on the conditions that may make Twitter effective for a seldomstudied but important group of political actors.

\section{Theorizing Twitter: Mediatization, Agenda Setting, and Network Effects}

Our analysis focuses on three possible communicative objectives to examine the strategic use of the Twitter tool among the frontbench Labour Lords. First, we discuss mediatization and suggest that in order to be effective, politicians' Twitter usage cannot consist simply of broadcasting partisan messages, but must also conform to the social norms of the platform. Second, we discuss the network effect and the extent that this facilitates influencing the public and political agenda. Third, we outline the importance of coherent framing of messages and how communication hubs might function to increase visibility and reach.

Mediatization. In the political communication literature, mediatization describes the way that political communication has adjusted to the norms of the media (Swanson \& Mancini, 1996), in particular television, but this can also be applied to social media (Lilleker \& Jackson, 2011). This perspective on mediated politics considers how the affordances of particular media might shape the communication patterns of political speech. Twitter is an important platform for the dissemination of news and information, and in that way has been found to serve the needs of journalists (Davis, 2010). Following authoritative sources on Twitter provides journalists the opportunity to capture "scoops," and because the 140 
character limit ensures brevity and enables quoting or paraphrasing, sources can often provide a quotable "soundbite" to accompany a story (Vergeer, Hermans, \& Sams, 2011). Equally, through hyperlinks, a Twitter user can deliver a short message as well as a link to a more developed article, their own post on a weblog, a speech, or a similar artifact from another individual or organization they support. Politicians, for example, might use Twitter in this manner to promote official communication from their own party or for self-promotion (Golbeck, Grimes, \& Rogers, 2010; Jackson \& Lilleker, 2011). Conforming to the methods for promoting any statement, for example by delivering a short, pithy "soundbite," or linking to a more developed press release, is one-way in which Twitter can be employed to aid news management.

Mediatization effects likely help to explain a number of the recent and wellpublicized political gaffes that played out via Twitter. In 2013, Prime Minister David Cameron had to respond to criticisms after a member of staff mistakenly endorsed an offensive Twitter account while responding to the Nairobi terrorist attack. Labour Member of Parliament Diane Abbott was forced to apologize in 2012 over tweets that were considered racially divisive. In 2011, Labour Shadow Chancellor Ed Balls mistakenly tweeted his name rather than entering it in the search box, making headlines for his ineptitude. What these examples demonstrate is the manner in which the intimate and immediate nature of Twitter's functionality can produce new and sometimes embarrassing sources of information, particularly when used by "elites." The attention paid to them by mainstream news media fuels what Chadwick (2011) refers to as the political information news cycle. The particular features of social media that can facilitate both media attention and public political participation relate to the way tools like Twitter blur the public and private spheres. Social media platforms ask individuals "to construct a member profile, connect to known and potential friends, and view other members' connections... enabl[ing] multiple and overlapping connections between varieties of distinct social spheres" (Papacharissi, 2011, pp. 304-5). Participatory media, to a greater extent than other forms of mass communication, accentuate the potential for the individual to manage their sociality while strategically constructing a hybrid public/private identity (de Certeau, 1984; Goffman, 1959). These developments are suggested to lead to a blurring of boundaries between professional and personal, both in terms of information and content that is made public, as well as interaction across different spheres of an individual's life. Social media can thus provide content that is immediate, uncensored, and newsworthy.

Gaffes seem to occur because the effects of mediatization are not, on their own, determinant. Strategic usage of Twitter requires learning and conforming to the observed behavioral rules of the Twitter community. Retweeting, using hashtags, and being responsive to other users' messages are the established norms for the platform. These are conventions that necessitate a more interactive strategy than many politicians are often comfortable with (Erickson \& Lilleker, 2012; Larsson \& Moe, 2012; Stromer-Galley, 2000). Aside from conventions in usage, there are also conventions in content; arguably although Twitter facilitates 
broadcasting it is not the right way to gather followers and become embedded within a network. It has been argued that users seek personally relevant and interesting newsfeeds, suggesting there are rules for gaining a following (Grant, Moon, \& Grant, 2010). For example, from an e-representation perspective it appears that a combination of personal, locally focused politics and serviceoriented tweets appear to be of interest to the general public and earn the tweeting politician a larger following (Jackson \& Lilleker, 2011). For many elected politicians, particularly in the United Kingdom and the United States, where there is a strong link to a geographic area, or even for Members of the European Parliament promoting their work in the legislature that links to the region or nation, the locality they represent is important (Lilleker \& Koc-Michalska, 2013). However, simply being political may not gain traction. Several scholars have remarked on the blurring between professional and personal identities in electronically mediated environments (Andrejevic, 2004; Lüders, 2008; Papacharissi, 2009). They argue that there is a potential impact on the network position and influence of an individual in balancing the personal and private, in particular by offering personal views on a range of political and social events that can stimulate interest within the Twitter community, as well as among journalists and other influential newsmakers, such as bloggers. Evidence suggests that for some politicians personalization is a clear strategy to earn some form of personal vote (Enli \& Skogerbø, 2013; Jackson \& Lilleker, 2011).

Therefore types of content, and the use of Twitter conventions may relate to the size of a following and so be a measure of overall social capital. Following and interacting with key individuals is suggested to be one-way for gaining reach. One can observe the flow of social capital among elite networks of well-known personalities through "public displays of connection" (Boyd \& Heer, 2006, p. 73). Mentions, possibly as a retweet, but also other forms of directed messages, prefaced by the @ symbol and an individual's user name, is a marker of a tie between users (Gilpin, 2011, p. 234). Gilpin (2011, p. 238) argues that identity is constructed "through a combination of associative patterns and communication content." We posit that these patterns can demonstrate levels of mediatization, as well as influence the mediation, within and beyond Twitter, for any user and their tweets.

Network Effects. The composition of a network is argued to be crucial for message dissemination, in particular when attempting to reach influential individuals. Politicians, in particular, use social media to gain traction for their messages within traditional media reports, as social media have become a popular means for monitoring politicians' views (An, Cha, Gummadi, \& Crowcroft, 2011; Erickson \& Lilleker, 2012). This mediation comes as a result of newspaper, television, or radio journalists redistributing messages online using their respective platforms, or paraphrasing or reproducing them within reportage (Broersma \& Graham, 2012; Vergeer et al., 2011). The challenge, however, is to have one's tweets read and forwarded by others. It has been suggested that to be influential on Twitter, like all social media tools, depends upon community formation (Ito, 2008; Java et al., 2007). Networked communities shape the architecture of 
information flows (Boyd, 2011), and a Twitter following can be visualized as a network with various degrees. The first degree would be direct followers, the second degree followers of followers and so on; the logic being that if any individual's followers retweet their tweet the reach will be extended out through the network (Anderson, 2007). Translated to political communication strategy, this tendency would suggest that political interests are best served by collectively mobilizing via online social networks, targeting influential users as well as increasing the reach and visibility of those working with one's collective. In practice this involves forming connections with allies, building a support network that aids in the counteraction of opposition forces, and reaching out to other mediators; so increasing the likelihood of setting the agenda through uptake of messages by traditional media journalists and bloggers.

Developing a following, however, is often reliant on offline status. Twitter serves as a new outlet for speakers who already belong to an elite, or who are at least affiliated with prominent positions in mainstream media or political life in general (Larsson \& Moe, 2012). It is likely that the followers of any political figure mirror the support existing in the offline environment. Within online environments these can appear as clustered networks-groups of individuals that function closely together, but that do not propagate ideas to a broader network (Himelboim, McCreery, \& Smith, 2013; McPherson, Smith-Lovin, \& Cook, 2001; Watts \& Strogatz, 1998). Politicians may generally exist in similar clusters, for example around issue-based campaigns or partisan affiliation more generally. Analysis of Twitter use by members of the German Reichstag shows that the network of politically vocal Twitter users consists of users who for the most part communicate with only a relatively limited number of users. Evidence suggests politicians tend to operate in close proximity to one another and work in networks that are self-referential and bounded by homophily. These networks act as both gate-openers (extending reach) but also gatekeepers (limiting access) to wider networks (see for discussion Jürgens et al., 2011).

The fact that research on politicians' use of Twitter shows they exist within tight-knit networks where "a very small number of highly interconnected users" operate (Jürgens \& Jungherr, 2011, p. 214) is unsurprising, as this would replicate their offline communication patterns. However, the problem with clustered, or closed, networks is that they have a limited ability to reach beyond that community. Closed networks form around a collective identity, common interests and goals (Livingstone, 2005) but need to reach beyond that network to capture wider attention. Political networks often resemble closed networks, connecting only along partisan lines (Bruns \& Highfield, 2013) and only promoting the party line, therefore allowing only limited or no interactivity (Small, 2010; Himelboim et al., 2013). Arguably elite networks such as these operate as "a form of colloquy, an ongoing discussion of interested professionals who congregate to discuss specific topics of interest and collectively negotiate definitions, applications, norms, and professional identities" (Gilpin, 2011, 245). Elite networks can be closed or open, although the intention is to share thinking with a wider network through their contacts. Politicians who join Twitter and become active users can 
form clustered networks, link into wider publics or form elite networks; each suggests a focus on developing different relationships with a range of other users in order to influence the agenda of the public sphere. These networks form from a closely interconnected cluster of users but tend to be exclusive and of little interest to users from outside that network.

It has therefore been argued that politicians face a double bind in adopting social media. Andrejevic (2006) highlights the need to avoid the gaffe, as the activities of elite actors may be constantly monitored by opponents (or journalists) waiting for anything that will represent a departure from expected norms of behavior. Even a minor deviation from the party line can lead to negative front page headlines. Yet to have voice any individual must be interesting, relevant to other users, and offer a more personal view. Hence politicians seek to connect to a range of users, in particular citizens (Graham, Broersma, \& Hazelhoff, 2013), while also linking with existing ego networks (influential nodes) that offer connections to important network positions (Verweij, 2012, p. 690). Previous research suggests that strategic social networking can enhance social capital (Ellison et al., 2011); we ask here if it can also enhance the agenda setting capacity (and therefore political capital) of elite individuals who may be marginalized by the mainstream media, and what network analysis can tell us about the position of individuals within virtual communities.

Agenda Setting. The often discussed potential of Twitter to augment political messaging is predicated on the notion of Twitter users being newsworthy. However, in a political context, research suggests that Twitter usage tends to build upon mediated events; Twitter users comment on televised leadership debates, for example, providing personal reflections as opposed to original information (Larsson \& Moe, 2012). Furthermore, many argue that Twitter acts as an echo chamber, propagating ideas from a single user or group through retweeting (An et al., 2011). There is therefore some debate whether Twitter acts as an agenda following or setting device and whether it offers scope for advancing issue-based campaigns (Morozov, 2012). Research is divided over this. Grant et al. (2010, p. 599) argue that "Twitter is becoming, ever more, the political space in Australia in which ideas, issues and policies are first announced, discussed, debated and framed." In Germany, Twitter was used as a tool by members of the Reichstag for informing supporters as well as journalists, defining the messages for the day and setting the agenda of a campaign (Jungherr, 2009). Yet, elsewhere Twitter appears to be a forum for sharing insights about news as opposed to making news (Jackson \& Lilleker, 2011).

Political parties in particular attempt to harness Twitter through combining the forces of their elected members and supporters to disseminate a consistent frame around an issue or policy. It is argued that delivering a consistent message, with a consistent frame, is a powerful persuasive tool as this can have a direct cognitive impact on receivers, leading to a coherent message being disseminated via other mediators (Reese, Gandy, \& Grant, 2001). A consistently personalized and emotive framing of the 2010 Haiti earthquake, largely delivered via social 
media, is argued to have had a significant impact on the mobilization of receivers from across the developed world (Muralidharan, Rasmussen, Patterson, \& Shin, 2011). Equally, social spaces have specific characteristics and functions, and so meet certain objectives for users, which shapes uptake; this suggests that framing can have a direct impact upon behavior (Robards, 2012). Framing has seldom been applied to social media, the above studies being exceptions, and never within the context of political communication. Our current analysis thus examines the extent to which strategic use of Twitter conforms to the notion of building a coherent frame within a political party in order to win support.

\section{Methods and Data}

The researchers recruited 21 individual Labour Party Lords with Twitter accounts as candidates for the study (see Table 1). Sample size was constrained by the nature of the research project, its sensitivity, and its reliance on tracking individuals' (semi) personal communications. The 21 Lords who agreed to take part in the project were recruited via a knowledge exchange project run by Bournemouth University and supported by the Labour Lords communication

Table 1. Labour Lords Twitter Usage, Metrics, and Network Centrality

\begin{tabular}{|c|c|c|c|c|c|}
\hline Name & Twitter ID & $\begin{array}{l}\text { Lifetime } \\
\text { Tweets }^{\mathrm{a}}\end{array}$ & Following & Followers & $\begin{array}{l}\text { Eigenvector } \\
\text { centrality }^{\mathrm{b}}\end{array}$ \\
\hline Robert Winston & @ProfRWinston & 113 & 20 & 17,484 & 0.00 \\
\hline Oona King & @Oona_King & 861 & 633 & 10,478 & 0.00 \\
\hline Paul Drayson & @lorddrayson & 1,913 & 862 & 10,044 & 0.00 \\
\hline Joan Bakewell & @JDBakewell & 391 & 260 & 6,448 & 0.45 \\
\hline Jim Knight & @jimpknight & 3,267 & 916 & 6,443 & 0.61 \\
\hline Valerie Amos & @ValerieAmos & 180 & 173 & 5,525 & 0.00 \\
\hline Steve Bassam & @StevetheQuip & 9,055 & 565 & 3,588 & $0.76^{\mathrm{b}}$ \\
\hline Glenys Kinnock & @GlenysKinnock & 430 & 168 & 3,451 & 0.08 \\
\hline Stewart Wood & @StewartWood & 947 & 382 & 3,191 & 0.26 \\
\hline George Foulkes & @GeorgeFoulkes & 1,686 & 1,077 & 2,939 & 0.45 \\
\hline Janet Royall & @LabourRoyall & 409 & 198 & 1,888 & $0.88^{\mathrm{b}}$ \\
\hline Angela Smith & @LadyBasildon & 1,828 & 187 & 1,441 & 0.21 \\
\hline Philip Hunt & @LordPhilofBrum & 1,356 & 151 & 1,429 & $1.00^{\mathrm{b}}$ \\
\hline Willy Bach & @FightBach & 411 & 143 & 1,133 & 0.31 \\
\hline Clive Hollick & @CliveHollick & 212 & 41 & 548 & 0.00 \\
\hline Maeve Sherlock & @MaeveSherlock & 567 & 279 & 496 & 0.38 \\
\hline Kamlesh Patel & @LordKPatel & 64 & 94 & 400 & 0.01 \\
\hline Maggie Jones & @WhitchurchGirl & 165 & 53 & 231 & 0.43 \\
\hline Wilf Stevenson & @Missenden50 & 219 & 216 & 143 & 0.19 \\
\hline Ray Collins & @Lord_Collins & 2 & 12 & 12 & 0.30 \\
\hline Dianne Hayter & @HayteratLords & 0 & 6 & 1 & 0.00 \\
\hline
\end{tabular}

Notes: ${ }^{a}$ Measured at the start of the study period, as an indicator of preexisting familiarity with Twitter platform.

${ }^{b}$ Eigenvector centrality (EV) is a measure of the influence of a given node in a network, similar to the PageRank algorithm used by Google to rank Web pages. EV is calculated by taking into account the relative prestige of all other nodes that are adjacent to a given node. Here, @mentions between Lords were used as an indication of a connection (edge) in the social network graph presented in Figure 4. 
team. The objective of the knowledge exchange activity was to share politically actionable research from the Bournemouth University Media School with participants, to improve their online communication proficiency. Consequently, all of the final participants were users of social media to varying degrees, but also possessed an interest in learning more about social media platforms, including Twitter. The 21 Lords who participated in the study had individual Twitter IDs, and their permission was given to track their Twitter communications using third-party software. All of the information gathered was publicly available and could have been coded by hand with increased expense of effort. The accounts were tracked from June 20 to September 28, 2012, dates which mark the last meeting with the Labour Party Lords as part of the consultation project, and the first day of a changed Twitter application programming interface which ceased open data mining of Twitter public accounts using third-party applications.

The data were collected using an online data collection service (http://ifttt. com), which collected all tweets shared by the sample accounts, including retweets and mentions, and stored them in text format. The data comprised some 4,363 tweets sent by the 21 individuals over the 3-month study period. This automatically gathered data included the Twitter ID of the sender of the tweet, the time and date of the tweet, the content of the message, and any recipients, links, or communicative functionality used in the message.

The raw Twitter data were then subjected to an additional level of analysis. A content analysis was devised to record qualitative information about the Tweets in the data set. A team of five research assistants from Bournemouth University were employed to record the content of tweets, which was carried out by entering variables case-by-case into a computerized questionnaire. For each tweet, the researchers recorded the presence of functionality (@mentions and \#hashtags) as well as the target of those functions. Message content was coded according to its purpose-political when mentions of party politics or issues in the media were mentioned and personal when other elements such as hobbies, pastimes, and personal interests were shared-and the scale of the issue under discussion (local, national, regional, or international). Any hyperlinks embedded in tweets were noted and analyzed according to the target of the link (personal page, political resource, journalistic resource). The researchers also made a determination about the formalness of the tone of the message, using a Likert-style scale to rate Tweets according to the care used in sentence construction, grammar and other formal rules of language. All 4,363 cases, along with the variables added by the human research assistants, were exported to SPSS (International Business Machines, Inc., Armonk, NY) for further analysis. Inter-coder reliability checks were performed on a subset of the data. The researchers used Krippendorff's alpha, deemed an appropriate method of assessing the variation between coders in this type of content analysis research (Hayes \& Krippendorff, 2007). A test on 140 entries produced a cumulative Krippendorff's alpha of 0.824, which is deemed acceptable, with the observed variation occurring in the nonstraightforward categorical variables, message content, and message tone. Message tone was not ultimately included in this analysis. 
In addition to recording information about their individual Twitter behavior, the researchers sought to analyze the extent to which the Labour Lords acted as a coherent group on the Twitter platform. To that end, the team first analyzed the connections between members of the group extant in the recorded data. The team created node and edge tables using the presence of @ mention links between Lords in the study group. For example, if Angela Smith sent a tweet mentioning Steve Bassam, that relationship was registered as an out-degree link from Angela Smith and an in-degree link to Steve Bassam. Social network graphs were then produced from the data to reveal communicative networks between users in the sample. The team created separate node and edge tables to reflect other relationships, for example between members of the study sample and journalists, and between members of the sample and popular hashtags. If two Lords used the same hashtag when tweeting, this would be revealed as two in-degree links to that hashtag. One limitation of this study is that we could only observe the behavior of the 21 Lords in our sample; network graphs of the relationship with outside communities and journalists are consequently one-way only.

Node and edge tables were imported into network visualization software Gephi version 0.8.2 beta (The Gephi Consortium, Paris, France) and used to create network graphs. The network of tweeting Labour Lords was subject to further analysis of network density, clustering, and average path length, to assess the coherency of the network when communicating with outside audiences (journalists and other Twitter users). Of significance to this study, the eigenvector centrality of individual Lords was calculated and compared to other metrics of Twitter usage (Table 1). The research team sought a correspondence between the centrality of Lords in the social network and other measures of their Twitter usage such as number of followers or volume of tweets, in order to evaluate the extent to which preexisting familiarity or popularity is linked to influence within the immediate peer group. Our findings, discussed below, suggest that preexisting popularity and status do not necessarily translate to influence within and beyond the immediate peer group on Twitter, a theme explored in greater detail further in this article.

Finally, the team sought to address the group coherence of the Labour Lords in the content of their Twitter messages. By ranking occurrences of the use of specific text around policy issues identified by hashtag use, the team identified two main political issues that occupied the bulk of the Lords' online political communications during the study period. The researchers then compared those tweets with official statements by party ministers on the same issue. Similarly, those official statements were subjected to word-usage ranking to find the most commonly used terms for comparison. Comparison of the most commonly used language in both sets of documents (official and tweeted) enabled the team to make a determination about the discursive similarities or differences in communication strategy. The result enabled the researchers to make some observations about the extent to which the Labour Lords acted as a mouthpiece for the party, or developed independent and distinct lines on policy. 


\section{Descriptive Results}

In Table 1, we present the sample of Labour Lords and provide detail about the previous experience of each on Twitter at the start of the study period. The 21 cases are ranked according to the number of followers each had on their respective accounts, as a means of assessing the Lords' popularity. Robert Winston, Oona King, and Paul Drayson had the most followers at the time of data collection. Interestingly, this commonly used metric of Twitter popularity does not appear to predict other measures of use or effectiveness. Neither did these popular users tweet the most frequently, nor were they central to the communicative network of Lords as measured by our social network graphing technique discussed below. While the sample of users is too small to make statistical inferences, it appears as though usage frequency (tweets), popularity (followers), and network centrality (interconnectedness) are not correlated and do not predict one another as might be expected. Furthermore, the distribution of all of the metrics (popularity, usage, network centrality) lends support to the notion that even within an elite group such as the Lords, there will be tremendous variation in skill and effectiveness in use of social media platforms like Twitter.

The overall distribution of tweets by the Lords sample during our study period is shown in Figure 1. We observe a high degree of skewness in the volume of Twitter activity across the sample of Lords members, with the four most active users accounting for 73 percent of all activity recorded during the study period, and one user, Steve Bassam, accounting for 49 percent of all tweets. The presence

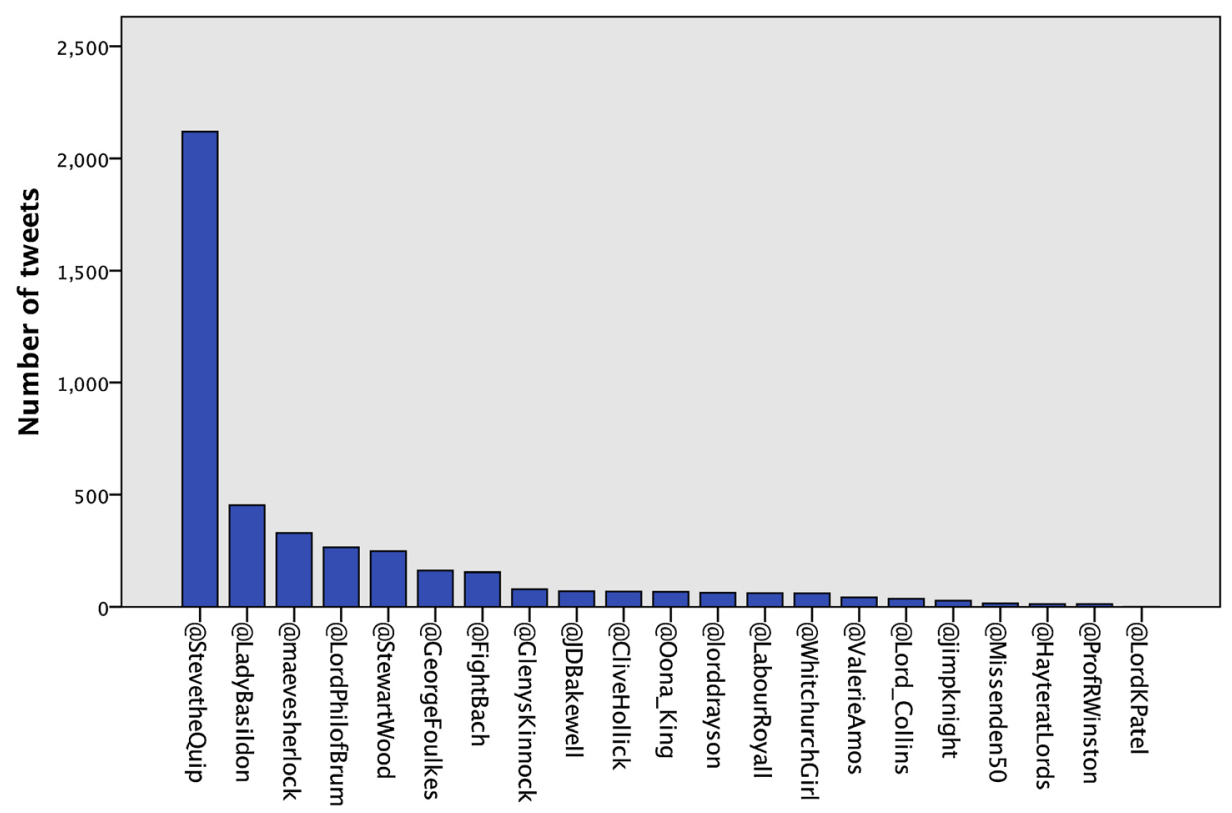

Figure 1. Frequency of Labour Lords Twitter Activity During Study Period. 
of natural breaks in the data suggests at least three groups according to intensity of Twitter usage. One group at the tail end of the graph tweeted less than 30 times over the period under study. A second intermediate group of individuals tweeted from 40 to 150 times over the course of the study, while a final group of heavy users tweeted over 200 times. The average for the entire Lords sample is 1.98 tweets per day, which compares closely with other concurrent studies that found a mean Twitter usage for all active users across the platform of 1.85 posts per day (Bennett, 2012). ${ }^{1}$ The overall distribution of tweets is consistent with other studies of Internet communication patterns that describe a "long tail" of moderate- to low-intensity contributors, with a small group of super-users at the head (Hindman, 2009; Mayfield, 2006). While the adherence of these data to the commonly observed power-law distribution in other online communication contexts might not be surprising, it is somewhat unexpected given that tweeting, for this group of participants, was encouraged by the Labour Lords media team as part of their day-to-day duties.

The research team's qualitative measure of the content of individual tweets supports the notion that Twitter is a hybrid platform, blurring private, and professional messaging. We found that on the whole, the Labour Lords in our sample tweeted on a range of topics, both public and personal, as shown in Figure 2. More than 65 percent of the tweets recorded in the analysis pertained to political issues, suggesting that the Lords are using Twitter primarily to communicate about politics. General political issues (not specifically related to Lords or Labour Party campaigns) comprised 20.1 percent of the sample of

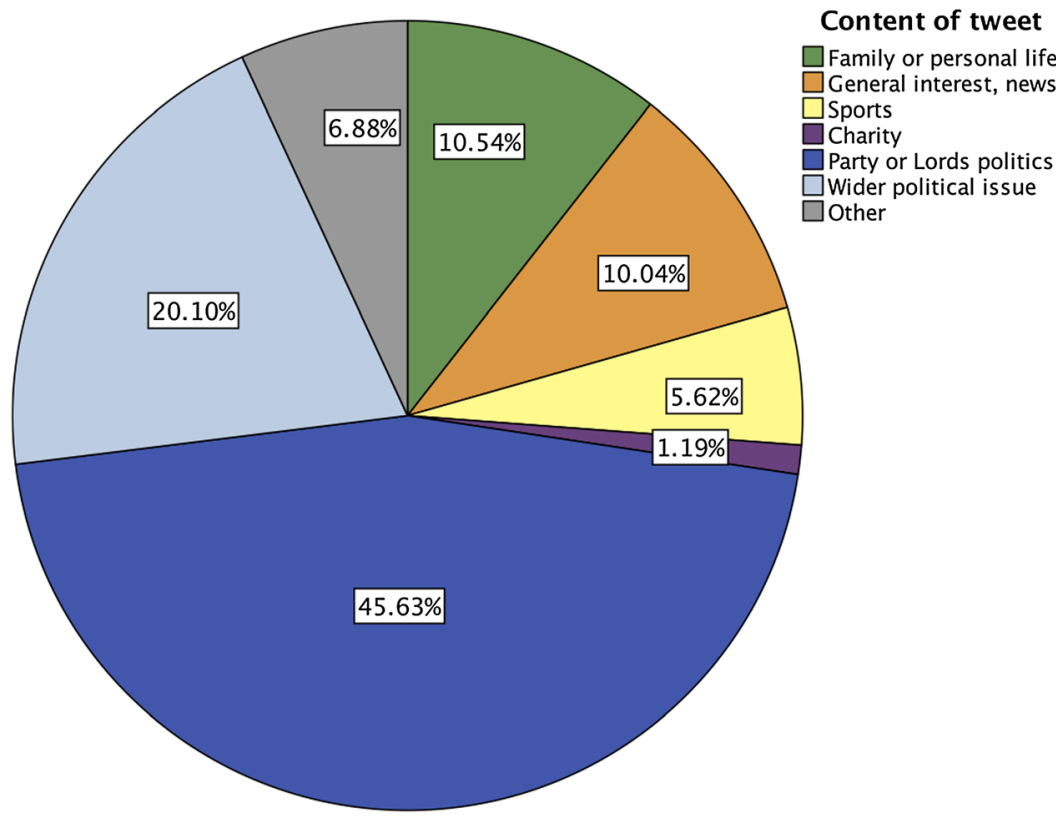

Figure 2. Content of Labour Lords Twitter Messages. 
individual tweets. A further 45.6 percent of the sample consisted of party political messages, either promoting Labour policy or attacking the coalition Government. Family and personal life were the next most frequently tweeted topics (10.54 percent) followed by nonpolitical general interest messages (10.04 percent) and sports related content (5.62 percent). Charity activity accounted for 1.19 percent of tweets in the sample. An additional 6.88 percent of tweets in the sample could not be categorized due to lack of context and were recorded as unknown/other. The data reveal that the overall distribution of topics varies across the sample, with variations in the frequency that Lords tweet about certain topics. It is notable that political messages made up the bulk of the content posted to Twitter by our sample of users. Other studies suggest that for the overall Twitter user base, politics is less frequently discussed: one recent U.K. marketing study found that only 0.5 percent of tweets by the public discussed political themes (Brandwatch, 2013). These results suggest that our sample is somewhat unique in its tactical use of Twitter to blend professional and personal issues, specifically using it as a platform to advance political arguments and ideas. However, the extent to which the Labour Lords' individual use of Twitter reflects strategic coordinated action is questioned later in the article.

In order to assess the possibility that Lords might behave differently on Twitter when its use was perceived to be part of their "work," the researchers examined the changing composition of tweet content over the course of the workday. The time (Greenwich Mean Time) that each tweet was sent was extracted and used to construct the graph shown in Figure 3. Colored bars

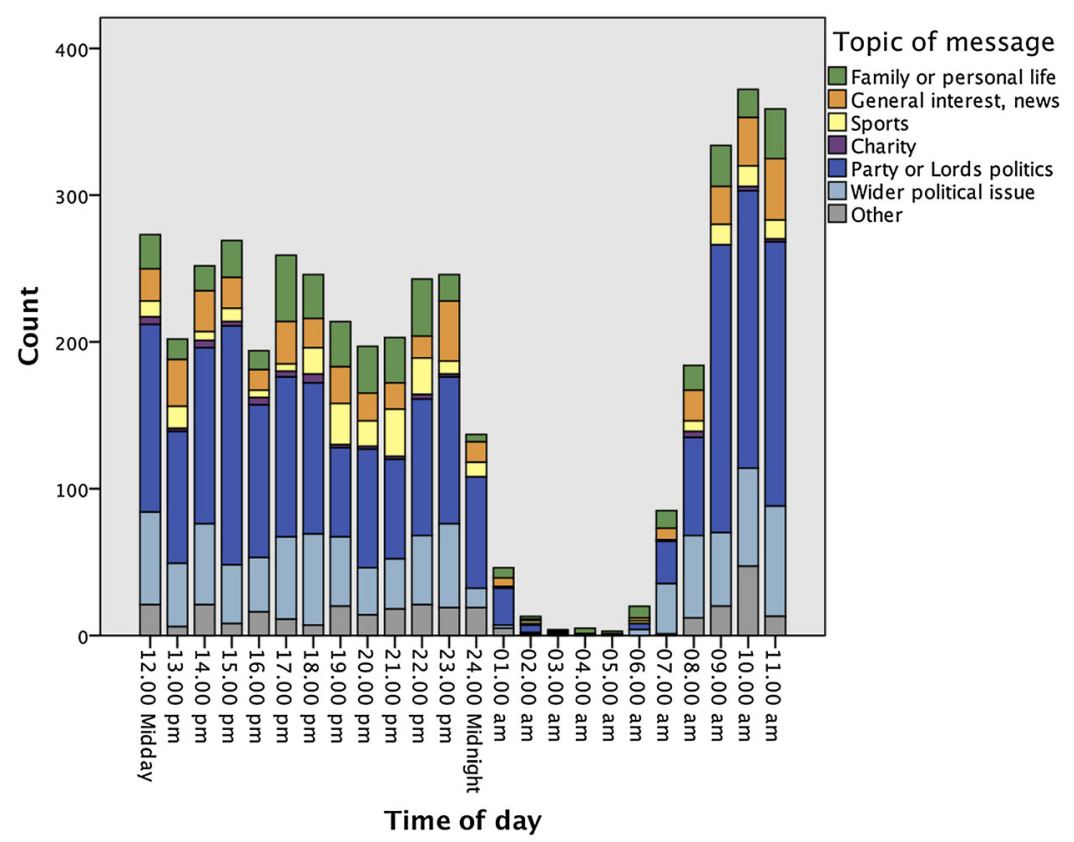

Figure 3. Average Daily Pattern of Twitter Usage by Labor Lords. 
represent the subject of the tweet, while the height of bars represents the average daily volume for that time of day. Peak activity occurs between 9 a.m. and 11 a. m., with consistent levels of activity from midday until 10 p.m., before activity drops overnight. While tweet volume varies throughout the day, the proportion of tweets focused on political and personal topics remains consistent. It appears that the Lords maintain an overwhelming focus on political themes at all times of day, even if the overall intensity of activity varies.

\section{Analysis and Discussion}

We have established that the peers of the Labour frontbench use Twitter to discuss personal and political issues, but that they do so with varying levels of intensity; some tweeted less than once per day during the observation period, while others tweeted many times per day. A few of the Lords had over 10,000 followers, while others had less than 100. Nonlinear distributions are commonly observed in online social networks, so these results on their own are not unexpected, and taken as a group, the Labour Lords tweet at a similar rate to the overall Twitter user base (Bennett, 2012). On the other hand, the subject of Labour Lords' tweets is disproportionately skewed toward politics when compared with average users. This suggests that the Lords are approaching Twitter with some strategic political objectives. If the Lords are using Twitter to discuss politics, to what extent are they effective in their use of the platform to advance their collective political agenda? Returning to the theories of mediatization, network effects and agenda setting, we assess the strategic effectiveness of the Lords' Twitter communications based on the data collected.

\section{Mediatization}

If Twitter is becoming part of the political communication strategy of the Labour Lords, one would expect usage to conform to the theoretical principles of mediatization, which holds that medium-specific features, used appropriately, are determinant in one's ability to transmit political ideas. We can observe the extent to which mediatization effects the way that the Lords in our study sample communicate on Twitter by evaluating their usage of specific Twitter functions (@ mentions, hashtags, and hyperlinks). In Table 2, we show how the Labour Lords made use of that functionality when discussing specific topics. Mentions were

Table 2. Lords Usage of Twitter Functionality by Content of Tweet

\begin{tabular}{|c|c|c|c|c|c|c|c|c|}
\hline Contains: & $\begin{array}{c}\text { Average } \\
(\%)\end{array}$ & $\begin{array}{c}\text { Family or } \\
\text { personal } \\
\text { life }(\%)\end{array}$ & $\begin{array}{c}\text { General } \\
\text { interest, } \\
\text { news (\%) }\end{array}$ & $\begin{array}{c}\text { Sports } \\
(\%)\end{array}$ & $\begin{array}{c}\text { Charity } \\
(\%)\end{array}$ & $\begin{array}{l}\text { Party } \\
\text { or Lords } \\
\text { politics } \\
(\%)\end{array}$ & $\begin{array}{c}\text { General } \\
\text { political } \\
\text { issues } \\
(\%)\end{array}$ & $\begin{array}{c}\text { Other } \\
(\%)\end{array}$ \\
\hline @ Mention & 63.1 & 70.22 & 59.36 & 53.47 & 73.08 & 59.42 & 60.21 & 97.00 \\
\hline \# Hashtag & 16.6 & 12.85 & 22.43 & 31.56 & 36.54 & 13.22 & 22.88 & 2.67 \\
\hline Hyperlink & 14.8 & 7.39 & 29.75 & 14.81 & 28.85 & 7.59 & 31.66 & 1.33 \\
\hline
\end{tabular}


used by the study sample in 63.1 percent of all tweets, with hashtags (16.6 percent) and hyperlinks (14.8 percent) less frequently used.

Depending on the topic under discussion, the Lords used each of the communication functions with differing levels of regularity. When discussing family or personal life, the presence of @ mentions was higher than the average for all Lords messages, suggesting that the Lords were using the functionality to communicate directly with family and friends on the Twitter platform. Hyperlinks and hashtags were used less frequently than average for personal tweets. The high degree of @ mention tweets in the uncategorized "other" category is consistent with those messages being simply replies to other Twitter users that were unclassifiable. Those messages also likely relate to communication with friends and family of the sender.

When the Lords discussed general interest topics, news, and politics, the use of hyperlinks was increased, suggesting that the Lords saw their function to direct readers to more information about a topic from an external source. Hashtags, which connect a tweet thematically to other tweets by way of a word preceded by the \# symbol, were most frequently used when discussing sports and charity topics, possibly as a means to connect with wider communities of interest, such as fans of a particular team or supporters of a particular social cause.

Interestingly, when discussing Labour political issues specifically, the usage of all three functionalities is lower than average. It appears that compared to other topics, Labour Lords' political issues are not as readily suitable to take advantage of these additional features of communication offered by Twitter. The use of @ mentions may be lower when discussing Lords' politics than other topic areas because the Lords have fewer individuals to target with the messages. They may tweet to one another about party messages, but this circle may not extend widely, or they may lack awareness of individuals who would be interested in a specific party message. The under-use of hashtags is surprising-we would expect that hashtag usage for party political messages would mirror that of nonparty general interest news stories. Surely the Labour Lords would wish to make use of hashtags to rally constituents around particular issues or campaigns. And finally, the low usage of hyperlinks to enrich party messages is unusual, considering the expected strategic objective of channeling audiences back to official party messages or resources. In summary, we find that mediatization is observed for all types of messages that Lords post on Twitter with the exception of Party messages, indicating potential lack of strategic fit between specific Twitter functionality and the usage by Lords of the tool as a party platform.

\section{Network Effects}

How expansive and coherent is the Lords' social network expressed on Twitter, and how well do the Lords coordinate their activities on the social networking platform? We were able to visualize one part of the Labour Lords' Twitter network by counting the number of times members in our sample used the @ functionality to message another member of the group (Figure 4). This 


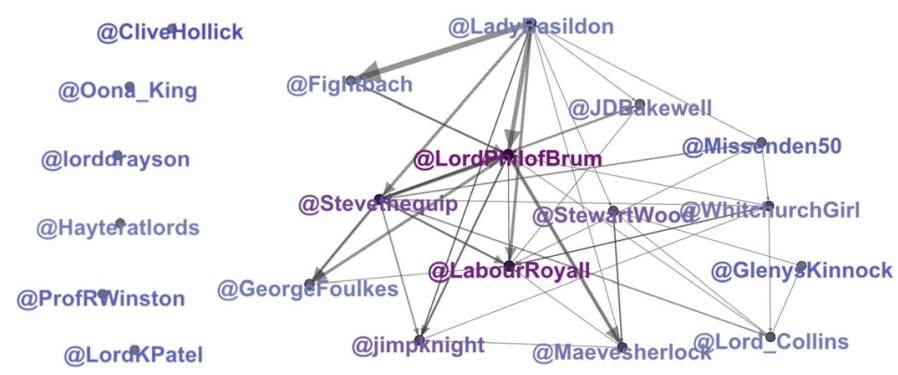

Figure 4. Network Graph of @ Mentions Between Sample.

network graph shows the connections between members of the House of Lords included in our study sample; each Lord in the sample may have additional connections outside of the study group. However, given that our sample consists of 21 active Twitter-using Lords from the same political party, a strong degree of interconnectedness between members of the sample is expected.

We find that interconnectedness with other Lords and centrality in the network is not dependent on preexisting influence or size of following on Twitter. In Figure 4, we define network centrality as the number of in-degree links pointing to a given member from the rest of the peer group (Wasserman \& Faust, 1994). If being mentioned by other members of the peer group is a measure of influence, then members with a larger number of incoming messages could be considered the most influential. We interpret an @ mention as a publicly visible acknowledgement of another Twitter user, and an indicator of that user's influence. The pattern of in-degree links suggests the emergence of a clique of centrally connected members in our sample (those with high eigenvector centrality) (Cheliotis, 2013). In-degree links are represented by the size and shade of the node labels. The users with the highest in-degree connections are @LordPhilofBrum, @LabourRoyall, @Stevethequip, and to a lesser extent, @jimpknight and @StewartWood. Each of the high-centrality users is linked with the others. In comparison, reciprocity in the overall network is low; @LadyBasildon is the second most prolific tweeter and the originator of the most @ mentions to other members of the sample, but she has a low number of in-degree links. A number of Lords in the sample are not connected to the rest of the members at all; these are represented in light gray on the left side of the graph. Based on the low degree of reciprocity and the relatively low network density of the Labour Lords sample, we can conclude that based on the criteria of @ mention linkages, the network exhibits a low degree of coherence, indicating a lower capacity for strategically organized action, beyond the core group of highly networked users.

How do the Lords interact with other influential figures beyond the immediate sample group of Labour peers? We further visualized the network, using one-way @ mention links not only between Lords but also with representatives of the media. Figure 5 shows the extended @ mentions from individuals in the sample to all external media sources. We identify five distinct 


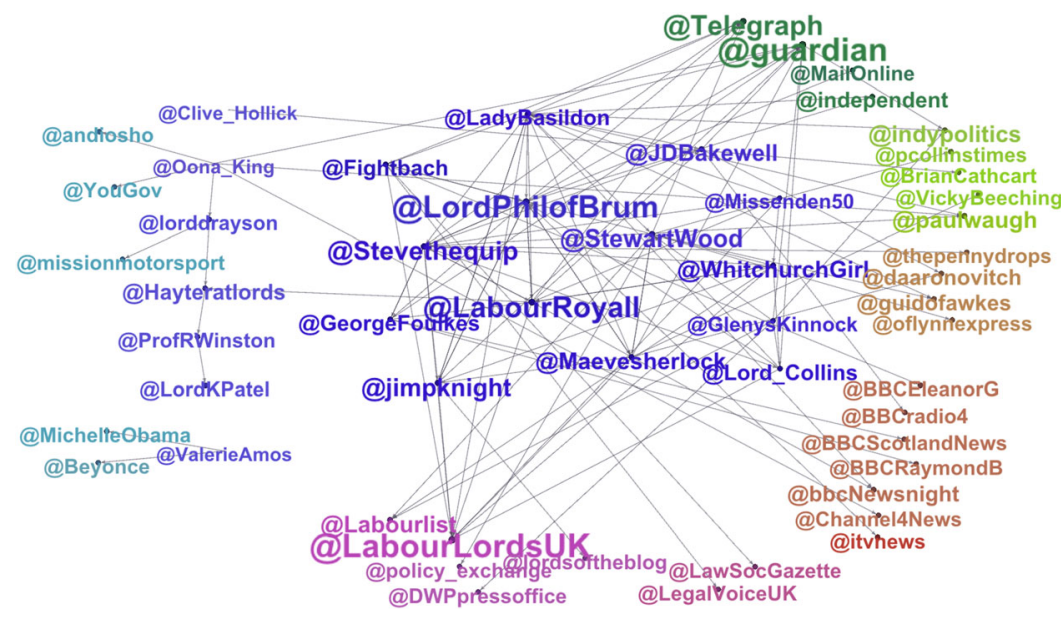

Figure 5. Network Graph of @ Mentions From Sample to External Media Sources.

types of media actors contacted on Twitter by members of our sample: (i) traditional newspapers, (ii) blogs, (iii) individual journalists, (iv) broadcasters, (v) think-tanks and media research organizations, (vi) Labour Party media platforms, and (vii) influential public figures and celebrities.

Interestingly, Labour peers in the sample most frequently reached out to traditional newspapers and their own Labour Party news organs when directing @ mentions toward the media. More than half of the sample (14) of individual peers sent at least two messages to a newspaper, tending to converge on either the Guardian or the Telegraph. A similar number of Lords (11) sent two or more messages directed at a Labour Party news platform. A number of peers were also strategic in their communications, sending messages targeted at specific journalists (such as Vicky Beeching), bloggers (such as Guido Fawkes), and broadcast news programs such as BBC Newsnight. Importantly, the majority of media mentions came from those members of the study sample that were already interconnected with other peers. The unconnected peers to the left of the graph sent few targeted messages to media platforms, suggesting their disengagement from the process of attempting to advance campaign issues through the traditional media via the Twitter platform.

In addition to media mentions, hashtags are a more direct way of advancing an idea or topic on the Twitter platform. If enough users of Twitter coordinate or converge around the same hashtag, that issue can become a "trending" topic that will appear in a ranked list of other popular topics. Preferential attachment and rich-get-richer dynamics generally lead to a vastly expanded audience for that topic, making the coordinated use of hashtags an important goal for campaigners and social movements. ${ }^{2}$

In order to visualize the Labour Lords' use of hashtags, we employed the same methodology as above: we identified a list of all hashtags with a political theme used by the Labour Lords, and counted each "use" as a link between that 
individual and that hashtag. Although this differs from the above social network graphs because hashtags are abstract concepts rather than individual targets, we can conceive of each hashtag as a distinct "node" in a network of other users. Since the purpose of using hashtags is to propagate a themed discussion via shared use, we sought evidence of shared use of hashtags among the Lords sample, indicating network connectivity around a specific campaign or activity.

In Figure 6, we illustrate the social network visualization of hashtag use by our study sample. The size and shade of node labels indicates the quantity of indegree links. There is significant diversity in the Lords' choice of hashtags, organized around three primary strategic uses: (i) advancing specific Party slogans or ideas, such as the anti-Legal Aid Reform campaign using \#LASPO; (ii) commenting on news stories of wider national and international interest, for example via the \#leveson and \#olympics hashtags; and (iii) drawing attention to a charity of interest such as \#Globalhunger and \#help2gether. It is significant that the rate of shared hashtag use is much lower than expected. In strategic communication by a group via Twitter, we would expect to see coordinated and shared use of hashtags to publicize and advance issue-based campaigns.

In Table 3, we summarize the network analysis of the three visualizations produced above: the Lords @ mention network, the network including mentions directed at the media, and the network of popular hashtags used by the peers. The overall density of the Lords Twitter network is low and compares to the density observed in studies of online interactions among complete strangers. For example, Russo and Nov (2010) studied the photo-tagging behavior of randomly selected and unrelated users of Flickr, and found a mean network density of

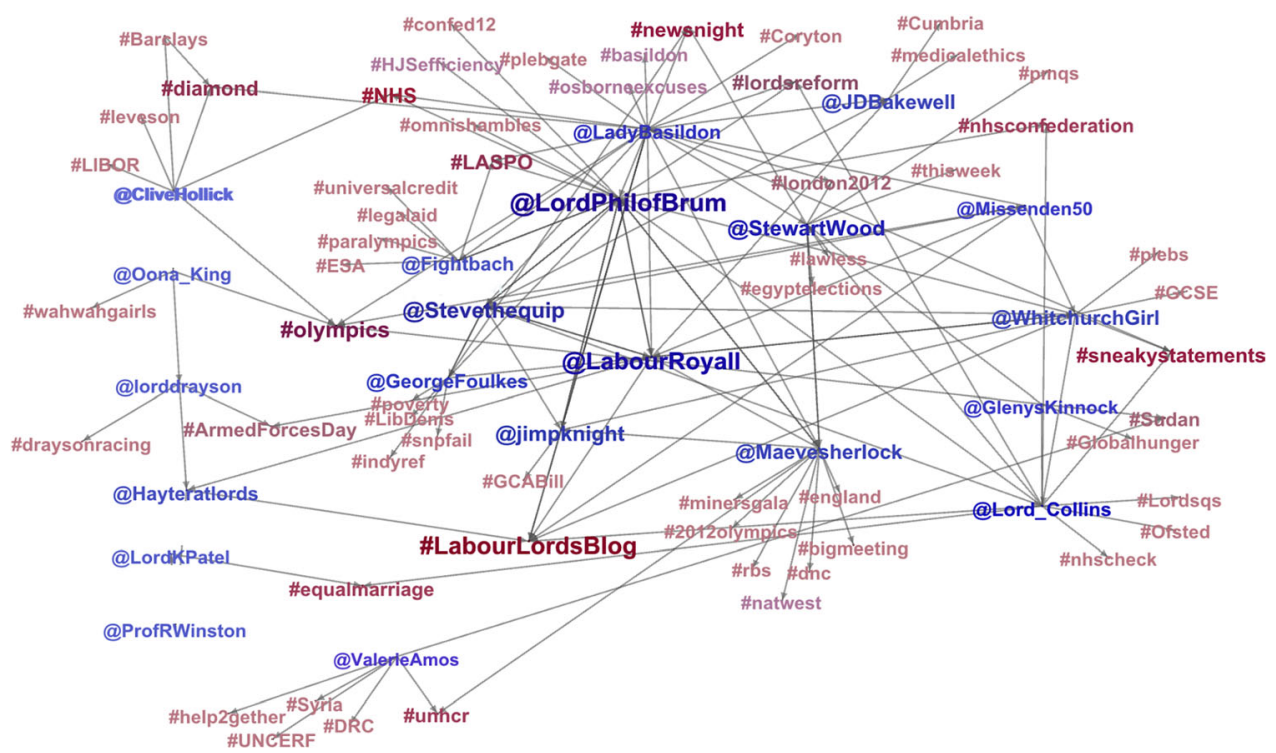

Figure 6. Network Graph of Shared Hashtag Use by Sample. 
Table 3. Network Density and Clustering for Three Graphs of Lords Twitter Activity

\begin{tabular}{lcccc}
\hline Graph: & $\begin{array}{c}\text { Average } \\
\text { degree }^{\mathrm{a}}\end{array}$ & $\begin{array}{c}\text { Undirected network } \\
\text { density }\end{array}$ & $\begin{array}{c}\text { Clustering } \\
\text { coefficient }^{\mathrm{c}}\end{array}$ & $\begin{array}{c}\text { Average } \\
\text { shortest }^{\text {path }}\end{array}$ \\
\hline Lords @ mentions & 2.61 & 0.21 & 0.52 & 2.13 \\
Lords + media @ mentions & 2.17 & 0.08 & 0.37 & 2.92 \\
Lords + hashtags & 1.72 & 0.04 & 0.26 & 3.38 \\
\hline
\end{tabular}

Notes: ${ }^{a}$ Average degree is the average number of edges connecting to each node in the network.

${ }^{\mathrm{b}}$ The ratio of the number of edges in a network over the number of total possible edges connecting all nodes. It is calculated as $n(n-1) / 2$ where $n$ is the number of edges in an undirected graph.

'In undirected networks, clustering coefficient $C$ of a node $n$ is defined as $C=2 e_{n}$ / $\left(k_{n}\left(k_{n}-1\right)\right)$, where $k_{n}$ is the number of neighbors of $n$ and $e_{n}$ is the number of connected pairs between all neighbors of $n$.

${ }^{\mathrm{a}}$ Average shortest path: average length of a shortest path between any given node $n$ and any other node. If $n$ is an isolated node, the path is calculated as zero.

0.227, based on the trail of comments left by users on one another's photos. On the other hand, studies of politicians' use of social media suggest that low-density networks might be a normally occurring phenomenon. For example, Hemphill et al. (2012) found a clustering coefficient of 0.229 when examining the @ mention network of members of the U.S. Congress, characterizing this as "low" compared to other social network studies with clustering coefficients in the range of 0.3-0.6. Our study of Lords @ mention behavior prior to adding media mentions or hashtags, with a clustering coefficient of 0.52 , falls squarely into this normal range.

A more interesting feature of the social network analysis is the difference in network characteristics between the Lords media mention graph and the hashtag graph. On average, nodes in the hashtag network are more isolated from one another (lower average degree). The network density is very low, with few hashtags shared between Lords users. Consequently, the average shortest path calculated for the Lords hashtag graph is longer, indicating that an observer would have to make a greater number of hops between Twitter user accounts to move from one issue to another in the network. We can also compute the clustering coefficient to determine the extent to which nodes are embedded in the network (Latapy, 2008). In its hub-and-spoke shape, the Lords hashtag usage graph more closely resembles an ego network (i.e., characterized by longer journeys between nodes via central gatekeepers) than a small-worlds network, which would be characterized by a shorter average path between nodes and higher clustering coefficient (see Gu, Huang, \& Zhang, 2013).

\section{Agenda Setting}

Our final analysis focuses on the extent to which we can detect coherent framing of partisan issues between the Labour Lords and the main party and the 
extent that the Lords act as focal points for communication of issues due to their offline status and expertise. According to Entman (1993, p. 52) "To frame is to select some aspects of a perceived reality and make them more salient in a communicating text." In order to determine the main themes embedded in the tweeting Lords' messages and therefore assess framing, it was necessary to undertake a deeper investigation into the overall content of messages. The large quantity of data collected (4,363 tweets or the equivalent to 860 pages of text) made traditional textual content analysis difficult. Therefore, instead of manually coding all tweets to identify the frames, the authors used software to isolate tweets that discussed one of the political issues under examination, and then counted occurrences of other words and phrases commonly occurring in the body of those tweets. First, we used SPSS to rank the usage of all hashtags, and we selected the top ranked two political hashtags from that list, \#laspo (relating to legal aid; 56 tweets) and \#lordsreform (48 tweets) for further analysis. The team manually extracted all tweets that contained those hashtags from the total sample, and used software Automap ${ }^{3}$ to remove numbers, prepositions, and other nonmeaningful contents of tweets. The aggregate text for each set of political tweets was then ranked for word-usage again, to identify the most commonly used language in the body of those political tweets. A similar process was used to identify commonly recurring phrases from the official party messages on the same topics. Official statements were identified from Labour Party sources, the text was prepared using Automap, and word-usage was subsequently ranked. This straightforward approach enabled us to identify the language most frequently used within public statements on policy made by the U.K. Labour Party and compare those with the content of the Lords' tweets, to gauge their proximity.

Due to the diversity of political issues advanced by the Lords, we chose to focus on the two most widely tweeted political issues: \#laspo and \#lordsreform. LASPO is a reference to the Legal Aid Sentencing and Punishment of Offenders Act 2012, which the Labour Lords opposed. The LASPO Act denied automatic rights to free legal support for those on low incomes where they were bringing a case before a court, for example divorce or civil claims. The \#lordsreform campaign centered on making the upper chamber more accountable, with suggestions for making some or all peers elected. For a better understanding of the extent to which Twitter discourses aligned with the Labour Party frames, we identified official Labour statements with regard to the two issues. An official statement opposing LASPO was made by Sadiq Khan, Labour spokesperson for Justice; a statement broadly supportive of Lords' reform but arguing the time was not right was made by Labour Leader Ed Miliband. Both were posted within the policy section of the main Labour website and so can be deemed official party policy (Tables 4 and 5).

We observe that in the case of LASPO, Sadiq Khan uses some highly emotive language, describing the reforms as an "onslaught" and "vandalism," and those who would lose the right to financial support as both "victims" and "sufferers." Terminology one might assume would be ideal to be converted into tweets to develop these frames. However, the most commonly used terminology within 
Table 4. Rank Order of Most Commonly Used Terms When Discussing the Legal Aid Issue Via (a) Labour Party Statements and (b) Twitter

\begin{tabular}{lll}
\hline Rank & $\begin{array}{c}\text { (a) Official statement by } \\
\text { Labour Party }\end{array}$ & $\begin{array}{c}\text { (b) Aggregate } \\
\text { Lords tweets }\end{array}$ \\
\hline 1 & Government & Aid \\
2 & Offenders & Legal \\
3 & Serious & Law \\
4 & Onslaught & Centre \\
5 & Access & Legalaid \\
6 & Justice & Advice \\
7 & Criminal & Cuts \\
8 & System & Congrats \\
9 & Victims & Lords \\
10 & Principled & Council \\
11 & Sufferers & Trial \\
12 & Vandalism & Fraud \\
\hline
\end{tabular}

Lords' tweets are procedural descriptors and none replicated the terminology in Khan's speech. In contrast, Ed Miliband's supportive statement on Lords Reform is largely descriptive with the terms "election," "proportion," and "democratic" setting out the party position. The Lords, however, use \#lordsreform to attack the coalition leaders Cameron and Clegg by arguing that its focus on Lords reform impeded the coalition from dealing with matters of greater importance during the economic recession.

As shown in the network graph in Figure 6, only a few Lords employed these issue-based hashtags. Largely, they focused on their own personal messages and interests rather than those of the party. These data reinforce the notion that to a certain extent the Lords work within ego networks, focusing on their own interests and promoting their own arguments, as opposed to offering a coherent opposition argument shared with their colleagues in the lower chamber of the

Table 5. Rank Order of Most Commonly Used Terms When Discussing the Lords Reform Issue Via (a) Labour Party Statements and (b) Twitter

\begin{tabular}{lll}
\hline Rank & $\begin{array}{c}\text { (a) Official statement by } \\
\text { Labour Party }\end{array}$ & $\begin{array}{l}\text { (b) Aggregate } \\
\text { Lords tweets }\end{array}$ \\
\hline 1 & \multicolumn{1}{c}{ Lords } & Lordsreform \\
2 & Bill & Bill \\
3 & Reform & Lords \\
4 & Second & Tory \\
5 & Chamber & Clegg \\
6 & System & Coalition \\
7 & Election & Reform \\
8 & Commons & Commons \\
9 & Proportion & Govt \\
10 & Democratic & Lord \\
11 & Scrutinize & Cameron \\
12 & Houses & Interesting \\
\hline
\end{tabular}


U.K. parliament. One might suggest that the nature of the different discourses is due to the constraints of Twitter as opposed to the descriptive space afforded by extended speeches or statements. However, in other political spheres it is a convention for either the original speaker or their supporters to tweet key sections of speeches and statements, so acting as cheerleaders (Jackson \& Lilleker, 2011). Equally, much of the rich and dense language contained in the official statements could be synthesized into 140 characters to repeat key phrases. Thus, it appears that rather than technology impeding this behavior it is the lack of a coordinated communication strategy and the personalized conventions of Twitter that lead to divergence in argumentation and presentation between the party and their frontbenchers in the upper chamber.

\section{Conclusions}

This article has examined the behavior of a privileged group of political actors on Twitter, to assess the degree to which their status affords them the ability to advance political issues via the social media platform. As a whole, we found that the Labour Lords in our sample are enthusiastic in their adoption of Twitter as a communication tool; they use Twitter at a rate comparable to the platform user base as a whole. They tweet more frequently about political issues than measures have shown for the overall user base, suggesting that they view this as an important objective for their use of the platform. However, we also observe significant variation in strategy and usage rates between individual Lords. Within the sample we identified a small group of highly networked users who tweet more frequently between themselves and with selected journalistic sources, but we also identified a number of lone tweeters talking to, and with, noone.

We find very little evidence of coordinated political activity by the Labour Lords on Twitter. Network reciprocity outside of the core group of five heavily networked Lords is low. Similarly, there does not appear to be any significant evidence of shared use of hashtags, a feature of Twitter communication that could be used strategically. Further, the content of political tweets, when composed by the Lords, does not reflect official Labour party messaging. However, while their use of hashtags is inconsistent, the Labour Lords make frequent use of the @ mention and embedded hyperlink facilities of Twitter, suggesting that mediatization is a factor in guiding the Lords to adhere to the conventions of the platform. However, this is weakest when promoting their official political activities in the Lords. Here, they seek to be agenda setters but are least likely to message other Lords, use hashtags, or include hyperlinks. Therefore, while they have adopted conventions in their overall communication, they have not adapted the functionality of Twitter to achieving collective political goals.

This research presents a number of practical implications for communication managers. Effective use of Twitter by a political community should involve close coordination between members of the group, to decide on shared campaigns, reinforcing one another's messages by providing centralized resources, for 
example, a blog or an official statement to include as a hyperlink in tweets. Frames, if not informed directly by the party line, could be coordinated between individuals so that tweets on a specific theme are searchable and contribute to advancing a given conversation via hashtags. Users who do not regularly tweet as part of the group, but who nevertheless may have large followings in other domains, could be particularly useful in such coordinated action, to extend and retweet political messages to their wider audiences.

In this article, we have sought to examine the social media practices of an unusual and understudied group of political actors. Although the Lords are a particularly unique political community, our findings lend support to other, related research on the composition of elite political networks and their behavior on Twitter. The mix of the personal and political among super-users stands out as a feature of groups of politicians within the Twittersphere (Enli \& Skogerbø, 2013). The emphasis on an insider group of networked individuals appears also to be a feature of political Twitter usage (Golbeck et al., 2010). The divergence from the party line does however indicate a sense of independence within this group of Lords that we would not expect to find among elected party politicians (Small, 2010). The similarities and differences indicate a fruitful route for further research, in particular, in focusing on political actors whose careers may not be dominated by electoral imperatives.

Much previous research presents snapshots of Twitter use by groups of actors across a range of polities. All are valuable contributions, but to gain a richer understanding of the role Twitter plays within strategic political communication, as well as how it feeds the political information cycle, more work is needed. One future direction for study could involve dynamic, time-series analysis of Twitter message propagation between political actors and influencers. For example, Nahon, Hemsley, Walker, and Hussain (2011) were able to demonstrate the leading role of elite blogs in propagating political news video across the Web, by examining the order of events in viral video lifecycles. Our study could be further extended to examine the original and subsequent spread of politically themed hashtags, to determine the role of elites in propagating political messages via their network. Second, more comparative work is required across nations, polities, and systems. An important question remains whether the observed social media behavior of politicians changes when electoral systems are different.

Our analysis is a step toward capturing the Twitter behavior of a small and somewhat unusual group of political actors. The Labour Lords are professional political agents who have conformed to many of the conventions of the platform; they are largely self-promoting and retain a sense of independence, maintaining an outsider status that in a way mirrors their position within the political arena. It is doubtful that such a strategy adheres to the expectations the party has of them, but the question remains whether Twitter is viable as a platform for coordinated political agenda setting, when followers may instead flock to more intimate, personal, and unscripted communication.

Twitter is an anarchic platform that allows users to combine personal and professional messages. The Lords choose what to tweet about, how to interpret 
policy initiatives and how to respond to coalition policy; this mirrors their offline work but online they have greater freedom in expressing personal beliefs and interests. The instantaneous practice of developing a cognitive response, typing it and tweeting means it is harder for a party to impose its will. Therefore, within the context of party politics, Twitter may not be a tool parties should encourage their elected (or unelected) members to use if the objective is coherent teamwork to push a party message into the online environment. Many politicians mirror the activities of this group, working in their personal ego networks, offering their own thoughts and intertwining the political with the highly personal and trivial. This begs the question whether tweeting should be left to the individual politician as opposed to party organizations attempting to direct and coordinate tweeting and building a chorus line of cheerleaders; it appears that the independence of the political actor is more sovereign than ever when given control over the send button.

Ana Adi is in the Media School at Bournemouth University

Kristofer Erickson is in CREATe at the School of Law, University of Glasgow [kristofer.a.erickson@gmail.com].

Darren G. Lilleker is in the Media School at Bournemouth University.

\section{Notes}

1. http://www.mediabistro.com/allTwitter/how-often-do-i-tweet_b19170.

2. Preferential attachment is a widely observed mechanism by which the distribution of new resources follows the amount of resources a given agent already has. The principle has been observed in networks to describe the skewed distribution of linkages to certain nodes; see Barabási and Albert (1999).

3. AutoMap is a text-mining tool developed by the Center for Computational Analysis of Social and Organizational Systems at Carnegie Mellon University. It is a relational textual analysis tool, but it can also be used to prepare and mine large bodies of text for word frequency.

\section{References}

An, J., M. Cha, K. Gummadi, and J. Crowcroft. 2011. “Media Landscape in Twitter: A World of New Conventions and Political Diversity." Proceedings of the 5th International AAAI Conference on Weblogs and Social Media. Barcelona, Spain 18-25.

Anderson, P. 2007. “What Is Web 2.0? Ideas, Technologies and Implications for Education." JISC Technology and Standards Watch Report, (February): 7-8.

Andrejevic, M. 2004. Reality TV: The Work of Being Watched. Lanham, MA: Rowman \& Littlefield.

Andrejevic, M. 2006. “The Discipline of Watching: Detection, Risk, and Lateral Surveillance." Critical Studies in Media Communication 23 (5): 391-407.

Bakardjieva, M. 2009. "Subactivism: Lifeworld and Politics in the Age of the Internet." The Information Society 25 (2): 91-104.

Barabási, A.-L., and R. Albert. 1999. "Emergence of Scaling in Random Networks." Science 286 (5439): 509-512.

Bennett, S. 2012. "Are You Addicted to Twitter? Here's How to Find Out." Mediabistro. http://www. mediabistro.com/allTwitter/how-often-do-i-tweet_b19170. 
Boyd, D. 2011. "Social Network Sites as Networked Publics: Affordances, Dynamics, and Implications." In A Networked Self: Identity, Community, and Culture on Social Network Sites, ed. Z. Papacharissi. London: Routledge, 39-58.

Boyd, D., and J. Heer. 2006. "Profiles as Conversation: Networked Identity Performance on Friendster." Paper presented at the Hawai'i International Conference on System Sciences (HICSS-39), January 4-7, Kauai, HI.

Brandwatch. 2013. “The Twitter Landscape 2013." Consulting Report. http://www.brandwatch.com/ wp-content/uploads/2013/02/The-Twitter-Landscape-2013.pdf.

Brenner, N. 1999. "Beyond State-Centrism? Space, Territoriality, and Geographical Scale in Globalization Studies." Theory and Society 28: 39-78.

Broersma, M., and T. Graham. 2012. "Social Media as Beat: Tweets as a News Source During the 2010 British and Dutch Elections." Journalism Practice 6 (3): 403-19.

Bruns, A., and T. Highfield. 2013. "Political Networks on Twitter: Tweeting the Queensland State Election." Information, Communication \& Society 16 (5): 667-91.

Chadwick, A. 2011. "The Political Information Cycle in a Hybrid News System: The British Prime Minister and the 'Bullygate' Affair." The International Journal of Press/Politics 16 (1): 3-29.

Cheliotis, G. 2013. "Social Network Analysis (SNA) Including a Tutorial on Concepts and Methods in Social Media." National University of Singapore. http://wiki.nus.edu.sg/download/attachments/57742900/Social\%20Network\%20Analysis.pdf.

Davis, A. 2010. Political Communication and Social Theory. London: Taylor \& Francis.

de Certeau, M. 1984. The Practice of Everyday Life. Berkeley: University of California Press.

Ellison, N., C. Lampe, C. Steinfield, and J. Vitak. 2011. “With a Little Help From My Friends” How Social Network Sites Affect Social Capital Processes. In A Networked Self: Identity, Community, and Culture on Social Network Sites, ed. Z. Papacharissi. London: Routledge, 124-45.

Enli, G.S., and E. Skogerb. 2013. "Personalised Campaigns in Party-Centered Politics: Twitter and Facebook as Arenas for Political Communication." Information, Communication E Society 16 (5): 757-74.

Entman, R.M. 1993. "Framing: Toward Clarification of a Fractured Paradigm." Journal of Communication 43 (4): 51-8.

Erickson, K., and D. Lilleker. 2012. “Campaign Websites and Hypermedia Campaigning: Lessons From the Ed Balls Labour Leadership Campaign 2010." Parliamentary Affairs 65 (2): 404-24.

Gilpin, D. 2011. "Working the Twittersphere: Microblogging as Professional Identity Construction." In A Networked Self: Identity, Community, and Culture on Social Network Sites, ed. Z. Papacharissi. London: Routledge, 232-50.

Goffman, E. 1959. The Presentation of Self in Everyday Life. New York, NY: Doubleday.

Golbeck, J., J.M. Grimes, and A. Rogers. 2010. "Twitter Use by the US Congress." Journal of the American Society for Information Science and Technology 61 (8): 1612-21.

Graham, T., M. Broersma, and K. Hazelhoff. 2013. “Closing the Gap? Twitter as an Instrument for Connected Representation." In The Media, Political Participation and Empowerment, eds. R. Scullion, R. Gerodimos, D. Jackson, D.G. Lilleker. London: Routledge, 71-88.

Grant, W.J., B. Moon, and J.B. Grant. 2010. “Digital Dialogue? Australian Politicians' Use of the Social Network Tool Twitter." Australian Journal of Political Science 45 (4): 579-604.

Gu, L., H.L. Huang, and X.D. Zhang. 2013. "The Clustering Coefficient and the Diameter of SmallWorld Networks." Journal Acta Mathematica Sinica, English Series 29 (1): 199-208.

Hayes, A.F., and K. Krippendorff. 2007. "Answering the Call for a Standard Reliability Measure for Coding Data." Communication Methods and Measures 1 (1): 77-89.

Hemphill, L., J. Ottenbacher, and M. Shapiro. 2012. "Relationships Among Twitter Conversation Networks, Language Use, and Congressional Voting." Paper presented at the International Communication Association Conference, May 24-28, Phoenix, AZ.

Himelboim, I., S. McCreery, and M. Smith. 2013. "Birds of a Feather Tweet Together: Integrating Network and Content Analyses to Examine Cross Ideology Exposure on Twitter." Journal of Computer Mediated Communication. 18 (2): 40-60. 
Hindman, M. 2009. The Myth of Digital Democracy. Princeton, NJ: Princeton University Press.

Howard, P.N. 2006. New Media Campaigns and the Managed Citizen. Cambridge: Cambridge University Press.

Ito, M. 2008. "Introduction." In Networked Publics, ed. K. Vernelis. Cambridge, MA: MIT Press, 1-14.

Jackson, N., and D. Lilleker. 2011. "Microblogging, Constituency Service and Impression Management: UK MPs and the Use of Twitter." The Journal of Legislative Studies 17 (1): 86-105.

Java, A., X. Song, T. Finin, and B. Tseng. 2007. "Why We Twitter: Understanding Microblogging Usage and Communities." In Proceedings of the 9th WebKDD and 1st SNA-KDD 2007 Workshop on Web Mining and Social Network Analysis, ACM 56-65.

Jungherr, A. 2009. “Twitternde Politiker: Zwischen buntem Rauschen und Bürgernähe 2.0." In Soziale Netze in der Digitalen Welt: Das Internet zwischen Egalitärer Beteiligung und Oekonomischer Macht, eds. C. Bieber, M. Eifert, T. Groß, and J. Lamla. Frankfurt am Main: Campus Verlag, 99-127.

Jürgens, P., and A. Jungherr. 2011. "Wahlkampf vom Sofa aus: Twitter im Bundestagswahlkampf 2009." Das Internet im Wahlkampf 201-25.

Jürgens, P., A. Jungherr, and H. Schoen. 2011. "Small Worlds With a Difference: New Gatekeepers and the Filtering of Political Information on Twitter." Proceedings of the ACM WebSci'11, June 14-17. Koblenz, Germany.

Karpf, D. 2010. “Online Political Mobilization From the Advocacy Group's Perspective: Looking Beyond Clicktivism." Policy E Internet 2 (4): 7-41.

Larsson, A.O., and H. Moe. 2012. "Studying Political Microblogging: Twitter Users in the 2010 Swedish Election Campaign." New Media E Society 14 (5): 729-47.

Latapy, M. 2008. "Main-Memory Triangle Computations for Very Large (Sparse Power-Law) Graphs." Theoretical Computer Science (TCS) 407 (1-3): 458-73.

Lilleker, D., and N. Jackson. 2011. Political Campaigning, Elections and the Internet: Comparing the US, UK, France and Germany. London: Routledge.

Lilleker, D.G., and K. Koc-Michalska. 2013. "Online Political Communication Strategies: MEPs, eRepresentation and Self-Representation." Journal of Information Technology \& Politics 10 (2): 190-207.

Livingstone, S. 2005. Audiences and Publics: When Cultural Engagement Matters for the Public Sphere. Portland, OR: Intellect.

Lüders, M. 2008. “Conceptualizing Personal Media." New Media E Society 10 (5): 683-702.

Mayfield, R. 2006. Power Law of Participation, Ross Mayfield's Weblog. http://ross.typepad.com/blog/ 2006/04/power_law_of_pa.html.

McPherson, M., L. Smith-Lovin, and J.M. Cook. 2001. "Birds of a Feather: Homophily in Social Networks." Annual Review of Sociology 27: 415-44.

Morozov, E. 2012. The Net Delusion: The Dark Side of Internet Freedom. New York: PublicAffairs.

Muralidharan, S., L. Rasmussen, D. Patterson, and J.H. Shin. 2011. "Hope for Haiti: An Analysis of Facebook and Twitter Usage During the Earthquake Relief Efforts." Public Relations Review 37 (2): 175-7.

Nahon, K., J. Hemsley, S. Walker, and M. Hussain. 2011. "Fifteen Minutes of Fame: The Power of Blogs in the Lifecycle of Viral Political Information." Policy E Internet 3 (1): 1-28.

Papacharissi, Z. 2009. “The Virtual Geographies of Social Networks: A Comparative Analysis of Facebook, LinkedIn and ASmallWorld." New Media \& Society 11 (1/2): 199-220.

Papacharissi, Z. 2011. “Conclusion: A Networked Self." In A Networked Self: Identity, Community, and Culture on Social Network Sites, ed. Z. Papacharissi. London: Routledge, 304-19.

Reese, S.D., O.H. Gandy, and A.E. Grant. 2001. Framing Public Life: Perspectives on Media and Our Understanding of the Social World. London: Routledge.

Robards, B. 2012. "Leaving MySpace, Joining Facebook: 'Growing Up' on Social Network Sites." Continuum 26 (3): 385-98.

Russo, P., and O. Nov. 2010. "Photo Tagging Over Time: A Longitudinal Study of the Role of Attention, Network Density, and Motivations." Fourth International AAAI Conference on Weblogs and Social Media 146-53. 
Small, T. 2010. "Canadian Politics in 140 Characters: Party Politics in the Twitterverse." Canadian Parliamentary Review 33 (3): 39-45.

Stromer-Galley, J. 2000. “On-Line Interaction and Why Candidates Avoid It.” Journal of Communication 50 (4): 111-32.

Swanson D.L., and P. Mancini, eds. 1996. Politics, Media and Modern Democracy: An International Study of Innovations in Electoral Campaigning and Their Consequences. Greenwood: Publishing Group.

Tremayne, M., N. Zheng, J.K. Lee, and J. Jeong. 2006. "Issue Publics on the Web: Applying Network Theory to the War Blogosphere." Journal of Computer-Mediated Communication 12 (1): 290-310.

Vergeer, M., L. Hermans, and S. Sams. 2011. “Online Social Networks and Micro-Blogging in Political Campaigning: The Exploration of a New Campaign Tool and a New Campaign Style." Party Politics 19 (3): 477-501.

Verweij, P. 2012. “Twitter Links Between Politicians and Journalists.” Journalism Practice 6 (5-6): 68091.

Wasserman, S., and K. Faust. 1994. Social Network Analysis: Methods and Applications. Cambridge: Cambridge University Press.

Watts, D.J., and S.H. Strogatz. 1998. “Collective Dynamics of "Small-World" Networks." Nature 393 (6684): 440-2. 